\title{
Aortic arch replacement without circulatory arrest or deep hypothermia: The "branch-first" technique
}

\author{
George Matalanis, MBBS, MS, FRACS, Nisal K. Perera, MBBS, and Sean D. Galvin, MBChB, FRACS
}

Objective: Although current developments in aortic arch replacement have demonstrated progressively improving mortality, cerebral morbidity remains significant. We describe a "branch-first" technique that avoids circulatory arrest and profound hypothermia, yielding excellent survival and low cerebral morbidity.

\begin{abstract}
Methods: From September 2005 to February 2014, 64 patients underwent the "branch-first" technique for aortic arch replacement. Each arch branch is individually isolated for a brief period while it is anastomosed to a perfused trifurcation graft. The disconnection-reconnection sequence proceeds from the innominate artery to the left subclavian artery, with uninterrupted perfusion of the heart and viscera. After reconstruction of the debranched arch and ascending aorta, the common stem of the trifurcation graft is anastomosed to the arch graft. In this series, there were 39 male patients, and the mean age was 65 (range, 17-85) years. Twenty-five cases $(39.1 \%)$ were of urgent/emergency status. Thirty-one patients $(48.4 \%)$ underwent operation for aortic dissection, and the remaining patients underwent operation for aneurysms. Sixteen patients $(25.0 \%)$ had previously undergone a cardiac surgical procedure.
\end{abstract}

Results: There were $2(3.1 \%)$ early mortalities, and 1 patient $(1.6 \%)$ had a permanent stroke. One patient $(1.6 \%)$ required mechanical support, and 4 patients $(6.3 \%)$ required hemofiltration for renal support. Ten patients $(15.6 \%)$ did not require transfusion of red cells or any other blood product.

Conclusions: The "branch-first" technique described brings us closer to the goal of arch surgery with cerebral, vital organ, and survival outcomes similar to those we expect from ascending aortic and root procedures.

(J Thorac Cardiovasc Surg 2015;149:S76-82)

Despite improving survival, surgery of the aortic arch continues to have a higher reported incidence of cerebral and other end-organ injury compared with surgery performed on the more proximal ascending aorta and root. ${ }^{1,2}$ Deep hypothermic circulatory arrest (DHCA) has been used extensively to reduce the cerebral and systemic organ metabolic rate. However, even short periods of DHCA are deleterious for higher cognitive function, and the incidence of cerebral and other end-organ injury increases proportionately with the length of DHCA. ${ }^{3,4}$ This means that the time available to complete a complex arch reconstruction using DHCA is limited, which may lead to a prematurely curtailed reconstruction or a hurried and technically suboptimal result. Although the widespread use of adjuncts, such as antegrade cerebral perfusion (ACP), combined with DHCA has lengthened the period

From the Department of Cardiac Surgery, Austin Hospital, University of Melbourne, Melbourne, Australia.

Disclosures: Authors have nothing to disclose with regard to commercial support.

Read at The American Association for Thoracic Surgery Aortic Symposium, New York, New York, April 24-25, 2014.

Received for publication April 24, 2014; revisions received July 3, 2014; accepted for publication July 21, 2014; available ahead of print Sept 16, 2014.

Address for reprints: George Matalanis, MBBS, MS, FRACS, Department of Cardiac Surgery, PO Box 5555, Heidelberg, Victoria 3084, Australia (E-mail: george. matalanis@austin.org.au).

$0022-5223 / \$ 36.00$

Copyright (C) 2015 by The American Association for Thoracic Surgery

http://dx.doi.org/10.1016/j.jtcvs.2014.07.100 of "safe" cerebral ischemic arrest and significantly reduced operative mortality from $15.2 \%$ to $8.5 \%$, temporary and permanent neurologic injuries have not decreased.

Since 2005, in an attempt to reduce the risks and morbidity associated with aortic arch replacement, our center has adopted a "branch-first" technique, in which there are no periods of global cerebral circulatory arrest or deep hypothermia. ${ }^{6,7}$ We describe our methods and report our early experience with this technique for replacement of the aortic arch in both elective and emergency settings.

\section{METHODS}

\section{Operative Technique}

Preoperative investigations include axial computed tomography angiography of the thoracic and abdominal aorta and transesophageal echocardiography. Intraoperative cerebral monitoring is performed by a combination of electroencephalogram bispectral index monitoring, cerebral oximetry (INVOS 3100; Somanetics Corp, Troy, Mich), and transcranial Doppler. In addition, bilateral radial and lower limb arterial pressure monitoring is performed routinely.

Our operative techniques have been described. ${ }^{6,7}$ Cardiopulmonary bypass is instituted via femoral arterial inflow and central, right atrial drainage. Left axillary or direct ascending aortic cannulation can be used in cases of thoracoabdominal atheroma or dissection with threatened malperfusion, although this was necessary in only 2 cases.

In our initial experience, left axillary cannulation was added to the femoral inflow to act as a source for antegrade perfusion to the arch branches as they were reimplanted into the trifurcation graft. In the last 39 patients, we replaced the need for axillary cannulation by the use of a 


\section{Abbreviations and Acronyms}

$\mathrm{ACP}=$ antegrade cerebral perfusion

$\mathrm{DHCA}=$ deep hypothermic circulatory arrest

modified trifurcation graft with an added perfusion side arm (Vascutek Ltd, Renfrewshire, Scotland, UK).

The arch branches are exposed for a length of 3 to $4 \mathrm{~cm}$ using a "no touch" technique. The innominate artery is clamped just proximal to its bifurcation and approximately $1 \mathrm{~cm}$ distal to its origin from the arch (Figure 1, A). The innominate artery is then divided between the clamps, and the proximal stump is ligated. The distal innominate stump is anastomosed to the first limb of the 3-branched graft (Figure 1, B). After the innominate artery anastomosis is completed, de-airing maneuvers are performed, and clamps are rearranged, antegrade perfusion is resumed from the right axillary artery inflow (early cases) or directly from the side arm of the trifurcation graft (later cases). Median cerebral perfusion flow was $1.0(0.8-1.4)$ liters per minute, with an aim to achieve a radial pressure of 50 to $70 \mathrm{~mm} \mathrm{Hg}$.

Completion of the innominate anastomosis removes tension on the convexity of the arch, increases its mobility, and enhances access to and exposure of the left carotid artery and in turn the left subclavian artery. A similar process is followed for the anastomosis and reperfusion of the second and third limbs of the branched Dacron graft to the left carotid and left subclavian arteries, respectively (Figure 1, $C$ and $D$ ).

When a large arch aneurysm interferes with access to the left subclavian artery, we use a number of maneuvers to facilitate its reconstruction. These include (1) using a short $(1-2 \mathrm{~cm})$ extension of the neck incision along the anterior border of the left sternocleidomastoid muscle, which can greatly improve exposure; (2) temporarily decreasing the distal perfusion pressure, which reduces the turgidity of the arch and avails more space; and (3) delaying the left subclavian reconstruction until the descending aorta is clamped and the arch resected, thus leaving ample room for left subclavian anastomosis.

At this stage, the perfused trifurcation graft easily can be laid out of the field, over the patient's neck. It is important to note that during this whole process the circulation is not interrupted to the heart or the distal organs. Also of note is that all arch branch anastomoses are readily in view, and complete hemostasis from these sites can be ensured with ease.

The proximal descending aorta is now readily mobilized. This can be assisted by temporary reduction in distal perfusion to increase its maneuverability. Also, division of the ligamentum arteriosum is key to allowing the recurrent laryngeal nerve to "drop away" from the aortic wall. Complete distal control was readily achieved in two thirds of the cases. In the remainder of patients, in whom this was difficult or there was a need to add an elephant trunk, periods of distal circulatory arrest alternating with periods of low distal flow with or without intraluminal balloon occlusion were used to allow the distal anastomosis to the descending aorta. After completion of the distal anastomosis, flow is changed from peripheral to central via a sidearm in the main graft. Once the proximal anastomosis is completed, the trunk of the branched graft is passed deep to the innominate vein and anastomosed to the ascending graft, in an end-to-side fashion, again without the need to interrupt cerebral perfusion (Figure 1, F).

\section{Data Collection and Analysis}

Clinical, operative, and postoperative data have been prospectively collected in a departmental database, with additional data extracted from review of the medical record. The use of these data has been approved for research purposes, and the need for individual patient consent was not required. Follow-up data were obtained from patient records and collected up to February 1, 2014. Continuous variables are expressed as median (first to third quartile). Categoric values are presented as absolute values (percentages).

\section{RESULTS \\ Patients}

Between September 2005 and February 2014, 64 patients have undergone this technique for total arch repair. Preoperative characteristics are summarized in Table 1 . Of note, $39.1 \%$ were of urgent/emergency status, $48.4 \%$ were type A dissections, and $25.0 \%$ had previous sternotomy for cardiac or aortic pathology.

\section{Extent of Aortic Replacement}

In dealing with the full extent of arch pathology, all $3 \mathrm{arch}$ branches required reimplantation in 31 patients $(48.4 \%)$, whereas in the remainder arch replacement stopped short of the left subclavian artery in 30 patients $(46.9 \%)$ and short of the left carotid in 3 patients $(4.7 \%)$. Concomitant aortic root procedures were performed in 39 patients $(60.9 \%)$ (Table 2).

Distal aortic reconstruction was performed in 15 patients (23.4\%), with 4 standard and 11 "frozen" elephant trunk procedures. Five patients underwent completion total aortic stenting for malperfusion or symptomatic true lumen compression.

\section{Perfusion Data}

The median lowest temperature was $27^{\circ} \mathrm{C}\left(22^{\circ} \mathrm{C}-28^{\circ} \mathrm{C}\right)$. The general target was $28^{\circ} \mathrm{C}$, with the lower range temperatures representing extra caution exercised early in our experience or in patients in whom distal circulatory arrest was needed. Individual arch branch clamp times were 14 (10-18) minutes for the innominate artery, 11 (9-14) minutes for the left carotid artery, and 18 (13-23) minutes for the subclavian artery reconstruction. Left subclavian artery reconstruction was longer because of its deeper position and a lower perceived urgency in the need to reperfuse it (Table 3).

\section{Early Postoperative Outcomes}

There were $2(3.1 \%)$ perioperative mortalities, with none in the elective operations. Both in-hospital deaths occurred before 30 days. Both occurred in patients with acute type A dissection with malperfusion syndromes ( 1 coronary, 1 bowel and lower limb). Both patients died of the ongoing effects of failure of the vital organ involved, despite correction of the cause of malperfusion by the operation (Table 4).

Three patients $(4.7 \%)$ had neurologic dysfunction. Two patients $(3.1 \%)$ had reversible neurologic events, 1 amaurosis fugax and 1 left hemiparesis. Both of these conditions resolved completely. These almost certainly occurred secondary to embolic events rather than hypoperfusion. Both early and delayed computed tomography of the brain in 


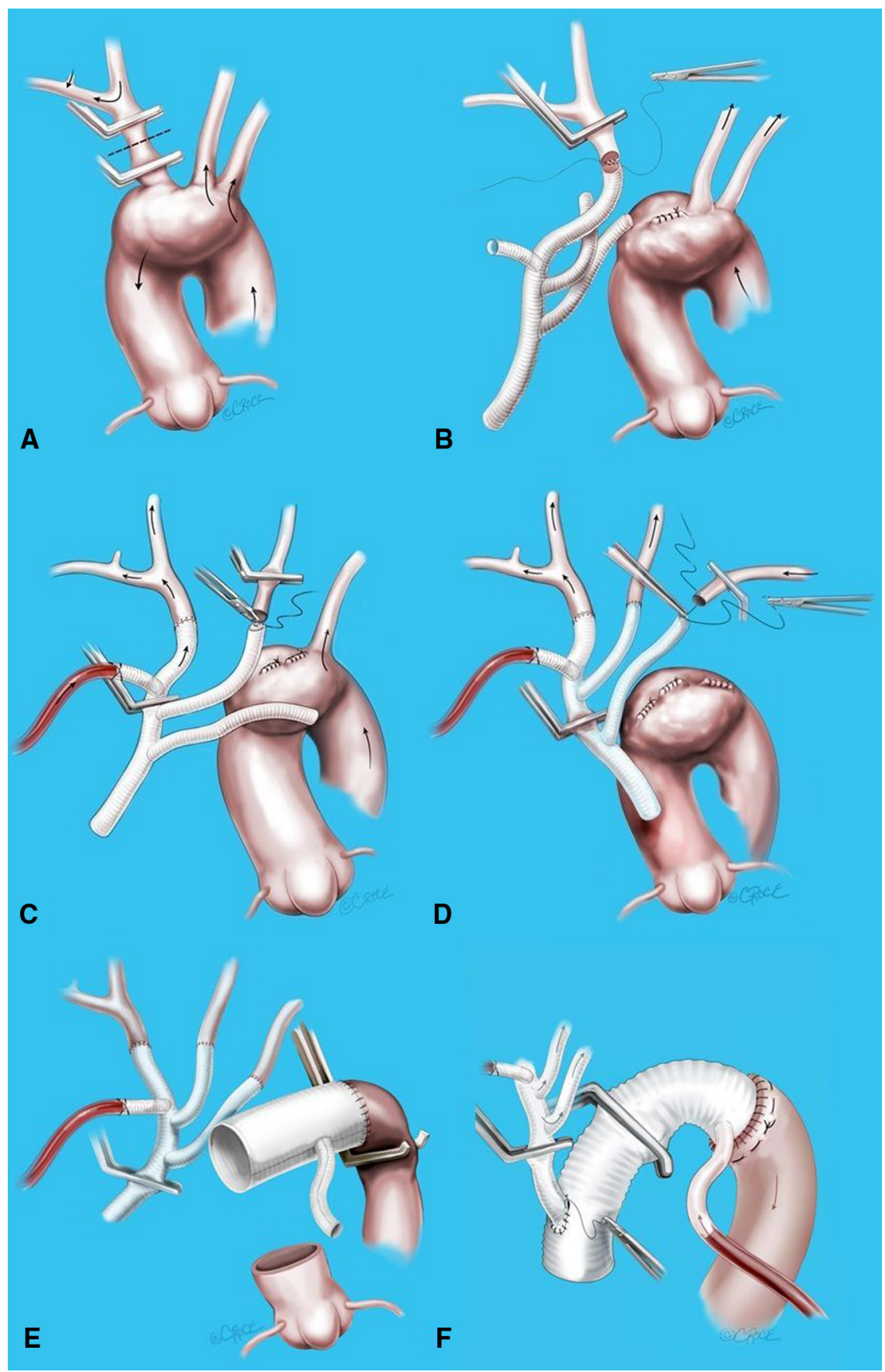

FIGURE 1. A, The innominate artery is clamped proximal to its bifurcation and distal to its origin from the arch and divided between the clamps. B, The innominate artery's proximal stump is ligated, and the distal anastomosis to the first limb of the 3-branched graft is performed. C, The second limb of the branched graft is anastomosed to the left common carotid artery. D, The third limb is attached to the left subclavian artery. E, Distal anastomosis of the arch graft to the distal arch. F, The trunk of the trifurcation graft is passed under the innominate vein and anastomosed to the arch graft. Reproduced with permission from Perera NK, Shi WY, Koirala RS, Galvin SD, McCall PR, Matalanis G. Outcomes of aortic arch replacement performed without circulatory arrest or deep hypothermia. Aorta. 2013;1:102-9.

both patients did not show any "watershed" infarction or hemorrhage. Dysphasia developed in 1 patient $(1.6 \%)$, which did not completely resolve. This occurred on the background of preexisting cerebrovascular disease and an acute type A dissection with cerebral malperfusion. There was also 1 case of persisting lower limb ischemia after central aortic repair. Other postoperative morbidity is summarized in Table 4. 
TABLE 1. Patient characteristics

\begin{tabular}{lc}
\hline & Patients (n= 64) \\
\hline Age, y & $65(54-73) *$ \\
Male & $39(60.9) \dagger$ \\
Smoking history & $30(46.9) \dagger$ \\
Dyslipidemia & $20(31.3) \dagger$ \\
Hypertension & $45(70.3) \dagger$ \\
Cerebrovascular disease & $5(7.8) \dagger$ \\
Coronary artery disease & $14(21.9) \dagger$ \\
Previous cardiac surgery & $16(25.0) \dagger$ \\
Status & \\
$\quad$ Elective & $39(60.9) \dagger$ \\
$\quad$ Nonelective & $25(39.1) \dagger$ \\
Type A aortic dissection & $31(48.4) \dagger$ \\
$\quad$ Acute & $21(32.8) \dagger$ \\
Chronic & $10(15.6) \dagger$ \\
Concomitant procedures & \\
$\quad$ Coronary artery bypass grafting & $8(12.5) \dagger$ \\
$\quad$ Nonaortic valve replacement/repair & $2(3.1) \dagger$ \\
\hline *Continuous variables expressed as median (interquartile range). $\dagger$ Categoric values \\
presented as absolute values (percentages).
\end{tabular}

Of note, 10 patients $(15.6 \%)$ received neither red blood cells nor any other blood products. Median time to extubation was 15 (11-38) hours, and more than $80 \%$ were extubated within 48 hours.

\section{DISCUSSION}

Although the widespread use of ACP in complex aortic arch repair has been associated with a reduction in operative mortality compared with DHCA alone, no significant impact has been made on neurologic morbidity, with temporary and permanent stroke risk remaining at $11.1 \%$ and $6.8 \%$, respectively. ${ }^{5}$ Several factors may account for this seemingly paradoxical observation. The beneficial effects of reducing time-dependent DHCA injury may be offset by manipulation of the arch and its branches associated with the insertion of antegrade perfusion cannulas, causing atheromatous or air embolism. Furthermore, periods of cerebral circulatory arrest are necessary for the initial positioning of the cannulas and again after their removal, possibly leading to hypoperfusion. Hypoperfusion also may arise as a result of cannula dislodgment, inadequate flows due to high line pressures, or direct branch injury or dissection.

Concerns also remain for other organ dysfunction, including renal failure, ischemic hepatitis, and even paraplegia, because many ACP strategies do not provide distal perfusion, relying on hypothermia alone for visceral protection, and these organs may become vulnerable in complex cases with prolonged circulatory arrest. Also, it is likely that whatever collateral circulation is provided to the systemic circulation by $\mathrm{ACP}^{8}$ is mostly lost in the presence of an open distal anastomoses. The resultant subclinical end-organ injury may contribute to the stormy and
TABLE 2. Extent of aortic replacement

\begin{tabular}{lc}
\hline & Patients $(\mathbf{n}=\mathbf{6 4})$ \\
\hline Extent of arch replacement & \\
Whole arch & $31(48.4)^{*}$ \\
To left subclavian & $30(46.9)^{*}$ \\
To left carotid & $3(4.7)^{*}$ \\
AV/root procedures & \\
Bentall's & $8(12.5)^{*}$ \\
Mechanical valve & $4(6.3)^{*}$ \\
Bioprosthesis & $4(6.3)^{*}$ \\
David & $6(9.4)^{*}$ \\
Other valve-sparing procedures & $23(35.9)^{*}$ \\
AV replacement & $2(3.1)^{*}$ \\
Distal aortic procedures & \\
Elephant trunk & $15(23.4)^{*}$ \\
Frozen & $11(17.2)^{*}$ \\
Regular & $4(6.2)^{*}$ \\
Total aortic stenting & $5(7.8)^{*}$ \\
\hline AV, Aortic valve. *Categoric values presented as absolute values $($ percentages $)$
\end{tabular}

prolonged postoperative course sometimes seen in these complex cases. Undoubtedly, the occurrence of clinically evident organ failure has a major impact on both perioperative morbidity and mortality.

Unilateral perfusion via right axillary cannulation avoids the need for direct arch branch cannulation with its inherent risks, while permitting uninterrupted antegrade perfusion for the duration of the arch repair. Moreover, the absence of cannulae traversing the operative field also provides better exposure. The technique has been criticized for its reliance on the adequacy of the circle of Willis, which can have significant anatomic variation and may be absent in approximately $15 \%$ of the population. ${ }^{9,10}$ However, the circle of Willis is only one of a number of rich collaterals that exists between the beds of the 3 arch branches. These additional collateral channels include those between the external and internal carotid arteries, the right and left carotid arteries, and the subclavian and carotid arteries. These extracranial collaterals allow for a short period of occlusion of one branch while the other 2 branches perfuse its territory and are particularly plentiful across the midline, especially in the tongue and thyroid. ${ }^{11}$ The ability of these channels to support collateral cerebral perfusion is supported by the infrequent occurrence of strokes after isolated common carotid, innominate, or subclavian ligation for various disease processes. ${ }^{12-14}$ The weakness of unilateral perfusion resides in the fact that only 1 of 3 branches is supplying the whole cerebral circulation. This puts a large stress on achieving the correct flow such that there is adequate contralateral hemispheric perfusion without the risk of ipsilateral hyperperfusion. Also, this delicate balance needs to be maintained for the whole duration of arch repair, which may exceed 1 hour in complex reconstructions. In a recent meta-analysis, 
TABLE 3. Perfusion data

\begin{tabular}{lc}
\hline & Patients $(\mathbf{n}=\mathbf{6 4})$ \\
\hline Innominate clamp time $(\mathrm{min})$ & $14(10-18)^{*}$ \\
Left carotid clamp time $(\mathrm{min})$ & $11(9-14)^{*}$ \\
Subclavian clamp time $(\mathrm{min})$ & $18(13-23)^{*}$ \\
Cardiopulmonary bypass time $(\mathrm{min})$ & $288(224-333)^{*}$ \\
Aortic crossclamp time (min) & $155(107-205)^{*}$ \\
Minimum temperature $\left({ }^{\circ} \mathrm{C}\right)$ & $27(22-28)^{*}$ \\
Distal circulatory arrest & $23(35.9) \dagger$ \\
Custodiol cardioplegia & $37(57.8) \dagger$ \\
\hline
\end{tabular}

*Continuous variables expressed as median (interquartile range). $\dagger$ Categoric values presented as absolute values (percentages)

although there was no difference in the temporary or permanent neurologic dysfunction between unilateral and bilateral antegrade perfusion, the cerebral morbidity remains significant. ${ }^{15}$

The advantages of the "branch-first" technique used in our center have been discussed in detail. ${ }^{6,7}$ The essential advantage is that there are no periods of global cerebral circulatory arrest. Similar to unilateral antegrade perfusion, use is made not only of the circle of Willis but also of the rich collateral network connecting the 3 arch branches. But, in contrast to unilateral antegrade perfusion, only 1 (rather than 2) of the 3 inputs into the collateral network is interrupted at any one time. Cardiac perfusion is maintained throughout the whole of the arch branch reconstruction phase, significantly reducing the period of time of reliance on cardioplegia and the risk of myocardial dysfunction. Maintenance of distal organ perfusion during arch reconstruction reduces the risk of postoperative vital organ dysfunction and postoperative bleeding and may shorten intensive care unit stays.

A further advantage of the branch-first technique is that the common stem of the trifurcation graft is translocated proximally, allowing a large landing zone should secondstage endovascular therapy be required. In patients with type A aortic dissection with postoperative symptomatic true lumen compression or organ malperfusion, we favor completion stenting to restore uniluminal aortic flow and reverse malperfusion. This combines a covered stent graft across the arch and upper descending thoracic aorta with bare metal stents and balloon-assisted intimal disruption to treat all remaining dissected aorta. In all patients, this was performed to the aorto-iliac bifurcation. This is combined with branch vessel stenting (visceral or iliac) as required.

Perioperative outcomes with the "branch-first" technique do indeed support the theoretic advantages. The $3.1 \%$ perioperative mortality rate in this series is extremely favorable compared with contemporary reports. ${ }^{16-20}$ Both mortalities occurred in patients presenting with acute type A dissection with malperfusion syndromes, well
TABLE 4. Postoperative outcomes

\begin{tabular}{|c|c|}
\hline & Patients $(n=64)$ \\
\hline In-hospital mortality & $2(3.1)^{*}$ \\
\hline Neurologic dysfunction & $3(4.7)^{*}$ \\
\hline Stroke & $1(1.6)^{*}$ \\
\hline Visual loss & $1(1.6)^{*}$ \\
\hline Hemiparesis & $1(1.6)^{*}$ \\
\hline Residual deficit & $1(1.6)^{*}$ \\
\hline Return for bleeding & $9(14.0)^{*}$ \\
\hline Tracheostomy & $3(4.7)^{*}$ \\
\hline IABP & $1(1.6)^{*}$ \\
\hline Renal support & $4(6.2)^{*}$ \\
\hline Ischemic gut & $0(0)^{*}$ \\
\hline Ischemic limb & $1(1.6)^{*}$ \\
\hline \multicolumn{2}{|l|}{ Transfusion } \\
\hline Red cells (units) & $2(0-5) \dagger$ \\
\hline Platelets (units) & $1(0-3) \dagger$ \\
\hline FFP (units) & $2(0-4) \dagger$ \\
\hline No red cells & $19(29.7)^{*}$ \\
\hline No red cells or other blood products & $10(15.6)^{*}$ \\
\hline Ventilation time (h) & $15(11-38) \dagger$ \\
\hline ICU time $(\mathrm{h})$ & $64(42-113) \dagger$ \\
\hline Length of stay (d) & $10(8-14) \dagger$ \\
\hline
\end{tabular}

recognized to have a high in-hospital mortality rate. ${ }^{21}$ In addition, the 1 permanent and 2 temporary cerebral morbidities are a strong testimony to the safety of this technique of cerebral protection. The low incidence of renal, cardiac, and respiratory complications attests to the quality of vital organ perfusion and protection. Finally, the low use of blood and blood components is a by-product of the easy access to all suture lines, the ability to conduct the reconstruction in a meticulous and an unhurried fashion, and the avoidance of the coagulopathy associated with deep hypothermia.

It is important to note that in the 9 patients who were returned to the operating room for bleeding, none had clinical tamponade, and on reexploration, none had a surgical cause of bleeding. We have a low threshold for returning to the operating room, and our policy has been to return the patient to the operating room for early reexploration if there has been more than $200 \mathrm{~mL}$ of blood out of the drain in 2 consecutive hours. Also, we have adopted a conservative use of blood products in our daily practice in an attempt to minimize blood product exposure and its inherent risk. A more liberal use of blood products may have resulted in a lower return to the operating room rate.

There was 1 case of left lower limb ischemia observed in this study. This occurred in a patient who presented with an acute type A dissection with visceral and lower limb malperfusion. The lower limb malperfusion persisted after 
central aortic repair. This patient eventually died of the ongoing effects of malperfusion. This patient underwent right femoral cannulation to institute cardiopulmonary bypass.

The "branch-first" technique represents a reliable and reproducible simplification in our surgical approach to arch reconstruction. Axillary cannulation was used in the early part of this series to provide direct right hemispheric cerebral perfusion during the period of innominate artery clamping. As confidence grew in the reliability of the extracranial collateral circulation, a technical simplification of avoiding right axillary cannulation was introduced. Now, in the first stage of the reconstruction, we use the same collaterals - in this case left to right - to provide right hemispheric protection during the brief period of innominate clamping. The inclusion of a prefabricated side arm to the trifurcation graft provides the inflow source for ACP in the place of axillary cannulation. With intraoperative cerebral monitoring, we have rarely seen cerebral desaturation during the innominate or left common carotid reconstruction using this technique. On the infrequent occasion that this occurred, adjustment of both systemic or cerebral flow rates and perfusion pressure rapidly returned cerebral oximetry levels to baseline. The reliability of this method of cerebral protection is supported by the frequently observed rapid awakening and lucidity of our patients, permitting early extubation in many of them. Although axillary cannulation has many proponents, it is not free of complications, such as retrograde dissection and malperfusion. It also carries low but definite risks of axillary artery and brachial plexus injury and leads to increased operative time and complexity. ${ }^{22,23}$ The latter is especially undesirable during emergency cases. Technical difficulties are more common in obese patients and those with fragile or small-caliber axillary arteries.

There are a number of potential disadvantages of this technique. Femoral cannulation has been implicated in retrograde embolization and the induction of malperfusion in acute dissection in some reports but not others. ${ }^{24,25}$ With the advent of modern preoperative and intraoperative imaging, it is possible to modify the cannulation site in relatively uncommon cases of thoracoabdominal atherosclerosis or dissections with unfavorable flaps that would favor malperfusion. There may be concern about the loss of security of the deep hypothermic "safety blanket" in case of unexpected findings. However, the fact that there are no periods of circulatory arrest in this technique means that one still has the facility to continue cooling whenever desired. The adoption of the trifurcation reconstruction technique adds the risks of graft kinking, stenosis, or inadequate caliber for total cerebral flow. With adequate care and planning, most of these technical issues can be eliminated. ${ }^{26}$ Care is still required to handle the aorta with a "no touch" technique to avoid the risks of embolic events from an atheromatous arch.

\section{Study Limitations}

The limitations of the series include its relatively small size, single surgeon bias, and evolution of technique over time. As more centers explore this technique and longer follow-up is obtained, it is hoped that we can become more confident in the technical facility and good survival and cerebral and organ protection of the "branch-first" technique for aortic arch repair.

\section{CONCLUSIONS}

This "branch-first" technique brings us closer to the goal of arch surgery without cerebral or visceral circulatory arrest and the morbidity of deep hypothermia. This technique simplifies a demanding procedure and has demonstrated excellent outcomes in our experience. Adoption by other centers and longer follow-up are required.

\section{References}

1. David TE, Armstrong S, Manlhiot C, McCrindle BW, Feindel CM. Long-term results of aortic root repair using the reimplantation technique. J Thorac Cardiovasc Surg. 2013;145(3 Suppl):S22-5.

2. Di Bartolomeo R, Pilato E, Pacini D, Savini C, Di Eusanio M. Cerebral protection during surgery of the aortic arch. Multimed Man Cardiothorac Surg. 2011 mmcts 2010004457

3. Reich DL, Uysal S, Sliwinski M, Ergin MA, Kahn RA, Konstadt SN, et al Neuropsychologic outcome after deep hypothermic circulatory arrest in adults. J Thorac Cardiovasc Surg. 1999;117:156-63.

4. Svensson LG, Crawford ES, Hess KR, Coselli JS, Raskin S, Shenaq SA, et al. Deep hypothermia with circulatory arrest. Determinants of stroke and early mortality in 656 patients. J Thorac Cardiovasc Surg. 1993;106:19-28.

5. Tian DH, Wan B, Bannon PG, Misfeld M, Lemaire SA, Kazui T, et al. A metaanalysis of deep hypothermic circulatory arrest alone versus with adjunctive selective antegrade cerebral perfusion. Ann Cardiothorac Surg. 2013;2:261-70.

6. Matalanis G, Koirala RS, Shi WY, Hayward PA, McCall PR. Branch-first aortic arch replacement with no circulatory arrest or deep hypothermia. J Thorac Cardiovasc Surg. 2011;142:809-15.

7. Galvin SD, Matalanis G. Continuous perfusion "Branch-first" aortic arch replacement: a technical perspective. Ann Cardiothorac Surg. 2013;2:229-34.

8. Miyamoto Y, Fukui S, Kajiyama T, Mitsuno M, Yamamura M, Tanaka H, et al. Analysis of collateral blood flow to the lower body during selective cerebral perfusion: is three-vessel perfusion better than two-vessel perfusion? Eur J Cardiothorac Surg. 2009;35:684-7.

9. Papantchev V, Stoinova V, Aleksandrov A, Todorova-Papantcheva D, Hristov S, Petkov D, et al. The role of Willis circle variations during unilateral selective cerebral perfusion: a study of 500 circles. Eur J Cardiothorac Surg. 2013;44 743-53

10. Merkkola P, Tulla H, Ronkainen A, Soppi V, Oksala A, Koivisto T, et al. Incom plete circle of Willis and right axillary artery perfusion. Ann Thorac Surg. 2006; 82:74-9.

11. Matalanis G, Shi WY. An Australian experience with aortic arch replacement: a novel approach without circulatory arrest or deep hypothermia. Heart Lung Circ 2011;20:163-9.

12. Lewin JS, Masaryk TJ, Modic MT, Ross JS, Stork EK, Wiznitzer M. Extracorporeal membrane oxygenation in infants: angiographic and parenchymal evaluation of the brain with MR imaging. Radiology. 1989;173:361-5.

13. Mitchell DG, Merton DA, Graziani LJ, Desai HJ, Desai SA, Wolfson PJ, et al Right carotid artery ligation in neonates: classification of collateral flow with color Doppler imaging. Radiology. 1990;175:117-23.

14. Allan JS, Wright CD. Tracheoinnominate fistula: diagnosis and management Chest Surg Clin N Am. 2003;13:331-41.

15. Angeloni E, Benedetto U, Takkenberg JJ, Stigliano I, Roscitano A, Melina G, et al. Unilateral versus bilateral antegrade cerebral protection during circulatory 
arrest in aortic surgery: a meta-analysis of 5100 patients. J Thorac Cardiovasc Surg. 2014;147:60-7.

16. Okada K, Omura A, Kano H, Sakamoto T, Tanaka A, Inoue T, et al. Recent advancements of total aortic arch replacement. J Thorac Cardiovasc Surg. 2012;144:139-45.

17. Iwasaki H, Satoh H, Ishizaka T, Matsuda H. Outcomes of single-stage total arch replacement via clamshell incision. J Cardiothorac Surg. 2011;6:114.

18. Kulik A, Castner CF, Kouchoukos NT. Outcomes after total aortic arch replacement with right axillary artery cannulation and a presewn multibranched graft. Ann Thorac Surg. 2011;92:889-97.

19. Matsuyama S, Tabata M, Shimokawa T, Matsushita A, Fukui T, Takanashi S. Outcomes of total arch replacement with stepwise distal anastomosis technique and modified perfusion strategy. J Thorac Cardiovasc Surg. 2012;143:1377-81.

20. Tanaka M, Kimura N, Yamaguchi A, Adachi H. In-hospital and long-term results of surgery for acute type A aortic dissection: 243 consecutive patients. Ann Thorac Cardiovasc Surg. 2012;18:18-23.

21. Di Eusanio M, Trimarchi S, Patel HJ, Hutchison S, Suzuki T, Peterson MD, et al. Clinical presentation, management, and short-term outcome of patients with type
A acute dissection complicated by mesenteric malperfusion: observations from the International Registry of Acute Aortic Dissection. J Thorac Cardiovasc Surg. 2013;145:385-90.

22. Sabik JF, Nemeh H, Lytle BW, Blackstone EH, Gillinov AM, Rajeswaran J, et al. Cannulation of the axillary artery with a side graft reduces morbidity. Ann Thorac Surg. 2004;77:1315-20.

23. Yilik L, Emrecan B, Kestelli M, Ozsoyler I, Lafci B, Yakut N, et al. Direct versus side-graft cannulation of the right axillary artery for antegrade cerebral perfusion. Tex Heart Inst J. 2006;33:310-5.

24. Gulbins H, Pritisanac A, Ennker J. Axillary versus femoral cannulation for aortic surgery: enough evidence for a general recommendation? Ann Thorac Surg. 2007;83:1219-24.

25. Kamiya H, Kallenbach K, Halmer D, Ozsoz M, Ilg K, Lichtenberg A, et al. Comparison of ascending aorta versus femoral artery cannulation for acute aortic dissection type A. Circulation. 2009;120(11 Suppl):S282-6.

26. Bischoff MS, Brenner RM, Scheumann J, Bodian CA, Griepp RB, Lansman SL, et al. Long-term outcome after aortic arch replacement with a trifurcated graft. J Thorac Cardiovasc Surg. 2010;140(6 Suppl):S71-6; discussion S86-91. 